\title{
PERSONAJES MASCULINOS QUE CUESTIONAN LOS ESTEREOTIPOS DE GÉNERO Y NUEVAS MULTIALFABETIZACIONES EN LOS LIBROS ÁLBUM: UNA MIRADA SISTÉMICO-FUNCIONAL Y SEMIÓTICO-SOCIAL
}

\author{
MALE CHARACTERS THAT CHALLENGE GENDER \\ STEREOTYPES AND NEW MULTILITERACIES IN \\ CHILDREN'S PICTURE BOOKS: A FUNCTIONAL \\ SYSTEMIC AND SOCIAL SEMIOTIC APPROACH
}

\author{
ROBERTO MARTÍNEZ MATEO \\ Universidad de Castilla-La Mancha \\ roberto.martinez@uclm.es
}

\section{RESUMEN}

El objetivo de este trabajo es identificar, en dos libros álbum donde los personajes principales cuestionan los estereotipos tradicionales de género masculinos, los recursos verbales y visuales utilizados por el/la autor/a y los ilustradores para estudiar sus sinergias en la construcción del mensaje global en el plano representacional. Mediante un análisis multimodal desde la Lingüística Sistémica Funcional de Halliday (2004) y la Semiótica Social Visual de Kress y van Leeuwen (2006), se identifican las elecciones en el modo verbal y visual adoptadas en cada texto de la muestra y luego se analiza su interacción.

Mayoritariamente, ambos modos se complementan para elaborar un mensaje común, aunque, en ocasiones, el peso del modo visual supera al textual en la construcción del significado debido a la complejidad de las imágenes (procesos visuales de acción y reacción, con procesos verbales y mentales). Por ello, es fundamental que los jóvenes reciban instrucción sobre las alfabetizaciones múltiples en la Educación Primaria.

Palabras clave: semiótica social, multimodalidad, género, metafunción representacional, alfabetizaciones múltiples. 


\section{Roberto Martínez Mateo}

\section{ABSTRACT}

The purpose of this work is to identify, in two picture books where the main characters challenge traditional male stereotypes, the verbal and visual resources used by authors and illustrators to study their synergies in the construction of the global message at the representational level. Through a multimodal analysis from Halliday's Functional Systemic Linguistics (2004) and Kress and van Leeuwen's Social Visual Semiotics (2006), I identify the choices in verbal and visual modes adopted in each of the sample texts and then I analyze their interaction.

Mostly, both modes complement each other to elaborate a common message, although the visual mode sometimes outweighs the textual one in the construction of meaning due to the complexity of the images (which combine visual processes of action and reaction with verbal and mental processes). Therefore, it is essential that young people receive instruction on the concept of multiple literacies in Primary Education.

Key words: Social Semiotics, Multimodality, gender, representational metafunction, multiliteracies.

\section{Objetivos y alcance del estudio}

La literatura es un gran instrumento para la adquisición de diversas competencias (Duff y Maley 1990; Millán 2000; Cassany 2006; Cerrillo 2010). Concretamente, la literatura infantil, mediante el formato del libro álbum donde conviven imágenes y texto en un mismo espacio, tiene la capacidad de contribuir enormemente a la educación de las jóvenes colectividades en valores sociales (Colomer 2018). Actualmente, los/las niños/as están sometidos al bombardeo de anuncios, al uso de Internet, la televisión, etc. y esta exposición les exige contar con unas capacidades de diversa índole (cognitivas, emocionales, alfabetización visual, etc.), que les permitan procesar la cantidad y variedad de estímulos y los distintos lenguajes a los que se enfrentan (Unsworth 2001, 2014).

En este sentido, Kümmerling-Meibauer (2015: 249) afirma que la literatura infantil y, específicamente, los álbumes ilustrados, juegan un papel crucial en la promoción de la adquisición de la primera y la segunda lengua. Del mismo modo, estos álbumes ilustrados facilitan también el aprendizaje de lenguajes simbólicos, así como la formación en las alfabetizaciones visuales y literarias (Kümmerling-Meibauer et al. 2015). Por ello es necesario instruir a los/las niños/as en las potencialidades de significación de las imágenes en su combinación con el lenguaje escrito, de lo que tradicionalmente carecen en el currículo de las etapas iniciales (infantil y 


\section{Personajes masculinos que cuestionan los estereotipos...}

primaria). Es tal el potencial significativo de las imágenes que se puede hablar incluso de una literariedad visual, en referencia a la capacidad de interpretar el lenguaje de las imágenes (Hanán Díaz 2007: 159). Esto exige la ampliación de los recursos y las prácticas interpretativas de los/las lectores/as para que sean capaces de extraer el sentido de estos textos tan complejos (Serafini 2012).

Los libros álbum permiten abordar innumerables temáticas. Los que aquí se analizan se adentran en cuestiones de género, una materia que cuenta con cierta tradición, como evidencia la existencia de estudios previos, como los realizados por Judith Evans (1995), Unsworth y Wheeler (2002), Mills (2008), Sunderland (2012), Janet Evans (2015), Martínez Lirola (2019, en prensa), Moya (2014) o Moya y Cañamares (en prensa), entre otros. Más concretamente, Sunderland (2012) revisa cómo se construyen las características de género en los libros álbum. Su análisis se basa en el Análisis Crítico del Discurso (Caldas-Coulthard y Coulthard 1996; Fairclough 2003) y en el análisis del contenido (Taylor 2003; Cohen et al. 2007), que muestran cómo, tradicionalmente, los personajes se perfilan a través del lenguaje en función de estereotipos predeterminados. De esta forma, los personajes masculinos adoptan roles más activos que influyen en otros/as participantes, mientas que los papeles desempeñados por personajes femeninos son de carácter más pasivo. Sin embargo, los estudios existentes se centran mayoritariamente en cuestiones de contenido, desatendiendo la incidencia de las estrategias verbales y visuales utilizadas por escritores/as e ilustradores/as en la representación de estos personajes, que ofrecen otros modelos de comportamiento alejados de los estereotipos tradicionales.

El objetivo del presente estudio es la identificación de los recursos visuales y verbales que se actualizan en los dos libros álbum seleccionados con el fin de determinar qué cualidades se atribuyen a la caracterización de los personajes masculinos: si se siguen los estereotipos tradicionales en los que el varón (niño) es el que porta el coraje, la decisión y la capacidad de acción, y la mujer (niña) desempeña un papel secundario relegado a otras tareas menos productivas (Gooden y Gooden 2001; Sunderland 2012). Asimismo, se analiza la interacción que tiene lugar entre la palabra y la imagen a nivel representacional (Halliday 2004; Kress y van Leeuwen 2006) para dilucidar el papel que desempeña en la construcción del mensaje, por una parte, de cada uno de estos modos semióticos por separado y, por otra, de forma conjunta. Consecuentemente, se incide en la necesidad de que los/las destinatarios/as de estas obras reciban la formación necesaria para poder desentrañar el complejo mensaje que encierran.

Este trabajo se estructura en cuatro partes. En la sección segunda se describe el marco teórico escogido para su análisis: la semiótica social multimodal. En la sección tercera se presentan los textos de la muestra, la metodología y el análisis que 
se ha llevado a cabo. Para ello, en primer lugar, se identifican los patrones de transitividad recurrentes (Halliday 2004; Kress y van Leeuwen 2006) utilizados en el modo textual por el/la escritor/a y en el visual por los ilustradores para desafiar los estereotipos de género en estos libros álbum. A continuación, la sección cuarta se ocupa de recoger las conclusiones y mostrar cómo colaboran el modo verbal y el visual para promover discursos progresivos de género.

\section{Aproximación a la Semiótica Social Visual y a la alfabetización visual}

La sistémica funcional de Halliday (2004) y la semiótica social de Kress y van Leeuwen (2006), posteriormente desarrollada por Painter, Martin y Unsworth (2013), constituyen un marco teórico válido para el análisis de libros álbum, dada su tradición en el estudio de texto en su contexto de producción y uso. Además, el concepto de alfabetizaciones múltiples (Kalantzis y Cope 2001; Unsworth 2001; Healy 2007) se ha convertido en la actualidad en un concepto formativo fundamental en las etapas iniciales del aprendizaje.

El origen del concepto de alfabetizaciones múltiples, nuevas alfabetizaciones o multialfabetismos aparece a mediados de los años noventa a cargo del New London Group, aunque ha sufrido posteriores modificaciones (Cope y Kalantzis 2009). Dicho concepto se basa en la adquisición y dominio de una serie de destrezas relacionadas con el empleo personal, social y cultural de unas herramientas y lenguajes de representación, entendidos más bien como una práctica social. La alfabetización múltiple implica la asunción de la existencia de la alfabetización multilingüística y la multimodal. Atendiendo a la afirmación de Kress (2010), quien expuso que el mundo que se relata se ha convertido en la actualidad en el mundo que se muestra, se hace imperiosamente necesario contar con unas destrezas en el ámbito cognitivo, emocional y social para posibilitar un desarrollo integral de la persona. En el caso de los/las más jóvenes, los libros álbum constituyen una herramienta de primer orden para promover la adquisición de la alfabetización visual.

Por su parte, la Lingüística Sistémica Funcional (LSF) de Halliday (2004) permite analizar en el plano lingüístico aquello que se representa, a quién afecta y los medios que se utilizan. A su vez, partiendo de esta visión lingüística de la LSF, Kress y van Leeuwen (2006) desarrollan su Semiótica Social Visual (SSV) como marco para el análisis de los recursos visuales empleados para la construcción del significado en textos multimodales. Así, el análisis de los textos multimodales de acuerdo con este marco teórico se corresponde con las elecciones tomadas de los sistemas semióticos que contienen opciones potenciales para crear significado. Kress y van 


\section{Personajes masculinos que cuestionan los estereotipos...}

Leeuwen (2006) asumen el planteamiento de Halliday de que en los textos se incluyen significados representacionales, interpersonales y textuales. En este sentido, Kress y van Leeuwen (2006) elaboran su gramática visual como marco para analizar la contribución de las imágenes en la construcción del significado estableciendo un paralelismo con las tres metafunciones hallidianas. Cada una de ellas por sí sola representa un amplio campo de investigación. También, al amparo de las directrices del proyecto de investigación AMULIT (véase agradecimiento final), se está llevando a cabo el análisis de las metafunciones en función de las posibilidades interpretativas que brinda cada una de ellas. En el presente estudio nuestro interés reside en la metafunción representacional, que se corresponde con la metafunción ideacional de Halliday.

Tanto desde la LSF como desde la SSV, la lengua se concibe como un sistema semiótico social donde los/las usuarios/as disponen de una serie de opciones para lograr sus objetivos comunicativos y construir significados en función del contexto social o de la cultura en que se inscriben (Lemke 1998; Halliday 2004; Unsworth 2006; Painter et al. 2013; Moya y Cañamares en prensa). Mediante las diversas elecciones dentro del sistema de transitividad de los procesos realizados por verbos, la función representacional se ocupa de la representación de los/las participantes, de los procesos en los que están involucrados/as y de las circunstancias donde se producen los diferentes tipos de procesos verbales. Para ello, Halliday (2004) establece una distinción básica entre procesos materiales, mentales y relacionales. Los procesos materiales son procesos de hacer, suceder, causar y transferir que reflejan los aspectos externos de la realidad, mientras que los procesos mentales reflejan los procesos internos de la consciencia e indican percepción, cognición, deseo, emoción y afecto. Además de estos dos procesos, existen los de clasificación e identificación, conocidos como procesos relacionales (tener, ser y llegar a ser). Finalmente, existen otros tres tipos de procesos, cuyas fronteras son menos claras: los de comportamiento, los verbales y los existenciales (Halliday 2004: 251). Los procesos de comportamiento son las manifestaciones externas de los aspectos internos de la experiencia. Por su parte, los procesos verbales son los que sirven para decir y comunicar información. Por último, mediante los procesos existenciales se reconocen, suceden o se introducen acontecimientos de diversa índole.

$\mathrm{Al}$ igual que la parte textual, las imágenes también poseen procesos visuales. De acuerdo con Kress y van Leeuwen (2006) y Painter et al. (2013), en el análisis de la función representacional de las ilustraciones también se puede diferenciar entre procesos narrativos, conceptuales y proyectados (véase Figura 1). En primer lugar, los procesos narrativos contienen vectores de movimiento para que los/las espectadores/as puedan crear una historia entre los/las participantes representados/as (en adelante PR). Estas ilustraciones pueden ser de acción (action), reac- 


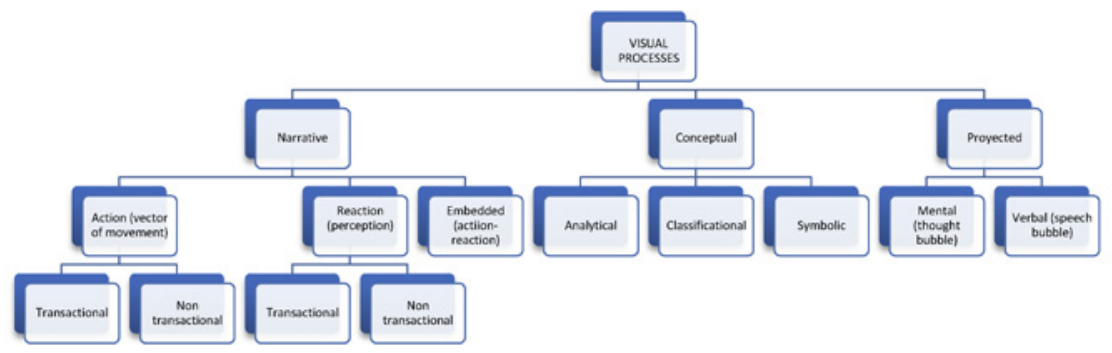

Figura 1. Procesos visuales (adaptado de Kress y van Leeuwen 2006 y Painter, Martin y Unsworth 2013).

ción (reaction) o de procesos compuestos (embedded), es decir, combinando procesos de acción y de reacción. Por su parte, las ilustraciones de acción, concretas o abstractas, pueden situar a un/una actor/a en situaciones transaccionales o no transaccionales. Las imágenes narrativas también pueden ser de reacción (reaction) y construir la narración mediante vectores oculares entre los/las PR y, del mismo modo que las de acción, pueden ser transaccionales y no transaccionales. Los procesos transaccionales, de acción o reacción, cuentan con un objetivo o fenómeno al final del vector, mientras que, en el caso de los no transaccionales, no aparecen como tal y los vectores carecen de direccionalidad. Además, los procesos de acción y reacción pueden combinarse dando lugar a la categoría de procesos compuestos (embedded).

Las imágenes conceptuales (conceptual), por su parte, carecen de vectores y suelen representar a los/las participantes en situaciones generales y atemporales, sin apenas contextualizar. Kress y van Leeuwen (2006) distinguen tres tipos de procesos conceptuales: los analíticos (analytical), donde los procesos relacionan a los/las participantes entre sí mediante una relación de la parte por el todo (Kress y van Leeuwen 2006: 93); las imágenes clasificatorias (classificational), que suelen aunar entidades para mostrar sus puntos en común y, por último, las simbólicas (symbol$i c$ ), que están asociadas a valores simbólicos. Finalmente, la categoría de los procesos proyectados (proyected) se bifurca en procesos mentales (mental) de cognición, que suelen realizarse mediante globos, bocadillos o burbujas de pensamiento, y los procesos verbales (verbal), que se expresan mediante globos de diálogo (véase Figura 1). Painter et al. (2013: 68) afirman que las acciones mentales y verbales no necesariamente incluyen vectores, sino que si vemos una imagen en donde un personaje tiene la boca abierta, nuestro conocimiento nos permite deducir que está hablando. 


\section{Personajes masculinos que cuestionan los estereotipos...}

Como dijimos anteriormente, en los últimos años proliferan los estudios que versan sobre la relación que se establece entre texto e imagen para la construcción del significado: Lewis (2001), Painter $(2007,2008)$, Unsworth y Ortigas (2008), Serafini (2010), Unsworth (2014) y Moya (2019). Estos estudios proponen taxonomías que plantean dicha relación como un continuo de relaciones que van desde la complementariedad a la contradicción. No obstante, en ocasiones, la interacción entre texto e ilustración no es clara, y además es cambiante dentro de una misma obra. Ahora bien, y de acuerdo con Painter et al. (2013: 6), la clave de esta cuestión reside en que la mayoría de estas taxonomías concebidas para analizar la sinergia texto-imagen únicamente permiten establecer un tipo de relación intersemiótica en cada composición o incluso en toda la historia. Por ello, Painter, Martin y Unsworth desarrollan un modelo intersemiótico basado en los conceptos de compromiso sistémico (commitment) y emparejamiento (coupling) (Painter et al. 2013: 134-143). Por una parte, el concepto de compromiso sistémico se refiere a las opciones de significado que son seleccionadas dentro de un sistema, en nuestro caso el sistema de transitividad, para representar una realidad específica en un texto concreto (véase Figura 1 como ejemplo de sistema de transitividad a nivel de la función representacional de la lengua). Respecto al compromiso sistémico aplicado a la metafunción representacional, Painter et al. (2013: 143) identifican tres dominios narrativos clave: la acción, el personaje y el contexto. Por otra parte, el concepto de emparejamiento hace referencia al patrón o uso recurrente dentro de un texto de realizaciones de dos o más sistemas.

Un ejemplo de compromiso sistémico sería la utilización conjunta de procesos narrativos verbales junto con procesos de acción y reacción visual en una representación concreta. Y cuando esta representación conjunta en ambos sistemas (visual y escrito) se dé con asiduidad, podremos hablar de que existe un patrón recurrente. La identificación de este patronaje repetitivo nos permitirá determinar si se dan casos de emparejamiento convergente o divergente a nivel representacional en los modos verbal y visual de los libros álbum objeto de estudio.

\section{Análisis de los textos de la muestra}

Tras la revisión de la Semiótica Social Visual y de la Lingüística Sistémica Funcional en la sección anterior, en este apartado se presenta el análisis de los dos libros álbum. Exponemos primero la metodología adoptada para llevarlo a cabo y una breve descripción de sus argumentos.

El análisis se realiza siguiendo una metodología mixta cuantitativa-cualitativa que nos ha permitido identificar, cuantificar e interpretar los recursos verbales y visuales empleados por el/la autor/a y por los ilustradores de los libros álbum para generar 


\section{Roberto Martínez Mateo}

discursos progresivos de género. En primer lugar, se señalan los procesos verbales en los que participan los personajes masculinos principales y, posteriormente, se analizan e identifican los procesos visuales en los que estos están involucrados y así se determina si los personajes bien se adaptan o bien rompen con los estereotipos tradicionalmente asociados al género masculino. Finalmente, se revisa la sinergia que se crea entre texto e imagen para establecer si la carga semántica que cada modo semiótico aporta a la construcción del significado es convergente o divergente, así como los patrones recurrentes de realización de significados que utilizan el/la autor/a y los ilustradores para generar mensajes progresivos que calen en el/ la joven lector/a.

Los dos libros álbum seleccionados son 10,000 Dresses escrito por Marcus Ewert e ilustrado por Rex Ray (2008) y The Purim Superhero escrito por Elisabeth Kushner e ilustrado por Mike Byrne (2013). Estos libros álbum forman parte del corpus del Proyecto AMULIT, que consta de cuarenta ejemplares subdivididos en cuatro secciones: diez títulos que muestran familias homoparentales cuyos padres sean dos hombres y otros diez que retratan a familias compuestas por dos mujeres; diez títulos que tratan las cuestiones de género y que tienen una chica como personaje principal y los diez restantes, con un chico como protagonista. La lengua materna de todos ellos es el inglés, por su difusión internacional. De este corpus de estudio, nos hemos centrado en el subapartado que tiene a los chicos como protagonistas y, dada la extensión de este trabajo, se han seleccionado dos ejemplares a partir de unos criterios comunes y de otros diferenciadores. Entre los comunes, el primero es que el público objetivo es un doble destinatario (Shavit 1986; Fernández 1996: 30), es decir, niños/as de entre siete y nueve años que probablemente comparten esa lectura con adultos/as, que son quienes seleccionan y guían la obra objeto de lectura; el segundo es que el argumento de los dos libros álbum aborda la cuestión de género, concebida como un constructo social, y la pone en tela de juicio; el tercero, que ambos libros álbum ofrecen una perspectiva amplia sobre las identidades de género y dejan en manos de sus protagonistas la capacidad de decisión final.

Sin embargo, pese a que los dos libros álbum seleccionados comparten como temática central la revisión crítica de los estereotipos e identidades de género, lo hacen desde contextos sociales diferenciados. En 10,000 Dresses, el joven Bailey se halla inmerso en un contexto familiar desfavorable ya que carece de la aprobación de su padre, de su madre y, sobre todo, de su hermano. Bailey se enfrenta al dilema interno de ser fiel a sí mismo y ponerse vestidos o de renunciar a su deseo para no disgustar a sus familiares. En cambio, Nate, el protagonista de The Purim Superhero, cuenta con el apoyo incondicional de sus dos padres. Este libro álbum, que celebra la cultura judía y una familia conformada por dos padres homosexuales (aunque 


\section{Personajes masculinos que cuestionan los estereotipos...}

ninguna de estas dos cuestiones se aborda explícitamente) es otro claro ejemplo de introspección interior en la búsqueda del verdadero yo. Con motivo del Purim, una festividad judía, todos los/las compañeros/as de clase de Nate se disfrazan de superhéroes, tal y como marca la tradición. Pero a Nate le encantan los alienígenas y se le plantea el dilema entre seguir la tradición o perseguir sus más profundos deseos, pese a ser diferentes a los tradicionales. Con el apoyo de sus padres homosexuales, Nate se decanta por enfundarse, por propia elección, un originalísimo atuendo de alienígena.

Una vez revisados brevemente los argumentos de los dos álbumes, en la siguiente sección se analizan los procesos verbales en los que participan ambos protagonistas.

\subsection{La representación de los participantes}

y los procesos en el modo verbal

A continuación, y siguiendo la propuesta de Halliday (2004) en relación con los tipos de procesos verbales expuesta en la sección segunda, se detallan los procesos relacionados con los protagonistas de los dos libros álbum.

En 10,000 Dresses, como muestra el Gráfico 1, Marcus Ewert utiliza en el modo verbal sobre todo procesos materiales y mentales para caracterizar al personaje principal, Bailey. Entre ambos acumulan el 87,49\% del total de los procesos identificados, dejando únicamente un 6,25\% a los relacionales, un 3,12\% a los verbales y otro $3,12 \%$ a los procesos de comportamiento. Bailey se sirve de procesos mentales transitivos para poder expresar sus sentimientos. Para ello se repite hasta en tres ocasiones la estructura del proceso 'amar': "With all her heart, Bailey loved the dress made of [...]", seguido de tres complementos distintos, uno por cada uno de los vestidos con los que sueña: 1) "crystals that flashed rainbows in the sun"; 2) "lilies and roses, with honeysuckle sleeves" y 3) "windows which showed the Great Wall of China and the Pyramids" (dobles páginas tercera, sexta y novena, respectivamente). Además, Bailey logra alcanzar sus deseos más profundos a través de procesos materiales (correr, hacer, etc.): "Bailey ran and ran. She ran all the way to the end of the block, until she came to a house with a big blue porch $[\ldots]$ " (doble página duodécima). Gracias a su total determinación, finalmente Bailey encuentra a Laurel, una amiga en la que halla la buscada aceptación ("That's awesome") y con quien consigue confeccionar sus anhelados vestidos: "Together the girls made two new dresses" (doble página decimotercera).

La abundancia de procesos materiales (53,12\% Gráfico 1) y mentales $(34,37 \%$, Gráfico 1) utilizados permiten trazar el perfil de la personalidad de Bailey como un niño tenaz y decidido que no duda en perseguir su sueño, pese al desdén y rechazo de sus familiares. Leemos incluso cómo la madre contribuye a perpetuar el discur- 


\section{Procesos narrativos textuales en 10,000 Dresses}

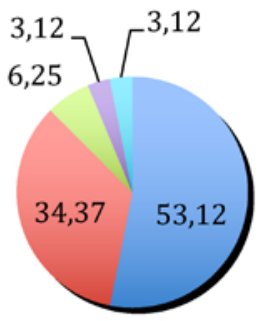

a Materiales

Mentales

Relacionales

- Comportamiento

nerbales

Gráfico 1. Valores porcentuales de los procesos narrativos textuales en 10,000 Dresses.

so patriarcal del estereotipo machista donde el hombre es el que se ocupa de las tareas productivas fuera del hogar mientras que es la mujer la que adopta un papel más pasivo encargándose de las tareas domésticas. Son numerosas las ocasiones que encontramos a lo largo del libro álbum donde tanto el padre y la madre como el hermano de Bailey responden bien con indiferencia ("Uh-huh") o bien con desaprobación ("That's gross", le espeta su hermano, doble página duodécima, o también "You are a boy. Boys don't wear dresses", le responde su madre, doble página quinta) a las constantes interpelaciones de Bailey en busca de su aprobación. El hecho de que "boy" aparezca en negrita no es baladí. La tipografía ${ }^{1}$ resaltada enfatiza la fuerza que la madre en este caso y posteriormente el padre y el hermano (dobles páginas octava y duodécima respectivamente) ponen en su discurso para recordarle a Bailey su condición masculina y también su reprobación.

Otro detalle que no se debe pasar por alto es el hecho de que desde el principio del libro álbum, cuando se hace referencia a Bailey a través de pronominalización, tanto en función de sujeto como de objeto, en lugar de utilizar el pronombre de género masculino "he/his" se utilizan los pronombres femeninos como "she" o "her": "When Bailey woke up, she went to find mother" (doble página cuarta). O cuando, en la octava doble página su padre le responde con indiferencia: "Uh-huh, said her father" (doble página octava). Sin lugar a dudas, estas opciones lingüísticas son todo menos casuales, y sirven para anticipar al/a la lector/a el desenlace final de la historia. Por su parte, el análisis de la transitividad en The Purim Superhero, al igual que en 10,000 Dresses, muestra un predominio de procesos materiales y mentales (véase Gráfico 2). De esta forma, Elisabeth Kushener emplea mayoritariamente procesos 


\section{Personajes masculinos que cuestionan los estereotipos...}

\section{Procesos narrativos textuales en The Purim Superhero}

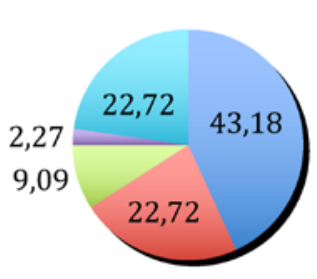

Materiales

घentales

Relacionales

- Comportamiento

Verbales

Gráfico 2. Valores porcentuales de los procesos narrativos textuales en The Purim Superhero.

materiales y mentales $(65,9 \%$, Gráfico 2$)$ para modelar la personalidad del personaje principal en relación con la diatriba a la que se enfrenta a lo largo de la historia: qué disfraz utilizar para la celebración de Purim. Como dijimos anteriormente, la tradición marca que los disfraces que se utilizan son normalmente de superhéroes, sin embargo, Nate, el personaje principal, desea disfrazarse de algo diferente, en concreto, de alienígena. Los procesos materiales transitivos (43,18\%, Gráfico 2) permiten construir la historia transmitiendo una sensación de movimiento y de progresión a medida que se suceden los acontecimientos que va realizando Nate, actor y protagonista activo de los mismos (pick up, scrunched up, put on, etc.). Asimismo, esta sensación de movimiento también va dejando entrever al/a la lector/a la determinación de Nate para tomar sus propias decisiones. Finalmente, Nate, siguiendo el cariñoso consejo de sus dos padres, no traiciona sus más profundos sentimientos y decide disfrazarse de alienígena, que es lo que realmente quiere: "He put on the alien suit that Abba had sewed, and the antenna and mask Daddy had bought" (doble página décima).

A su vez, los procesos mentales $(22,72 \%$, Gráfico 2$)$ contribuyen a la construcción de la historia mediante verbos que, principalmente, expresan voluntad (love, miss, want, wish) y que permiten a Nate expresar sus gustos y deseos: "Nate loved aliens, he loved to read about them" (doble página segunda). En última instancia, es también a través de los procesos verbales transitivos como Nate da voz a su debate interno: "Abba?, Nate asked, Do you ever just to want to be like everybody else?" (doble página duodécima). De esta forma, Nate hace partícipe al/a la lector/a de su dilema interno. 


\section{Roberto Martínez Mateo}

\subsection{La representación de la realidad en el modo visual}

Tras efectuar el análisis de la transitividad en el modo verbal de estos dos libros álbum en la sección anterior, ahora se aborda la representación visual de los personajes masculinos protagonistas. Posteriormente, en la sección 3.3 se determina en qué medida contribuye cada uno de estos modos al desarrollo de la historia y a la construcción de los personajes. Para estudiar la representación visual de los/las $\mathrm{PR}$, se analizan las elecciones adoptadas por los ilustradores con relación a los patrones de transitividad visual que se actualizan en los libros álbum para retratar a los dos niños protagonistas, Bailey y Nate.

Ahora, siguiendo la taxonomía de la propuesta adaptada de Kress y van Leeuwen (2006) y Painter et al. (2013) (Figura 1) sobre los tipos de procesos visuales, se especifican los procesos en los que participan los protagonistas en los álbumes de la muestra. En el libro álbum 10,000 Dresses, como se expresa en la Tabla 1, predominan las imágenes compuestas $(64,28 \%$, Tabla 1$)$ de acción y reacción, con proyecciones mentales de cognición $(35,71 \%$, Tabla 1$)$.

\begin{tabular}{|c|c|c|c|c|c|}
\hline \multicolumn{4}{|c|}{ PATRONES DE TRANSITIVIDAD EN 10,000 DRESSES } & $\begin{array}{l}\text { Valores } \\
\text { absolutos }\end{array}$ & $\begin{array}{l}\text { Valores } \\
\text { relativos }\end{array}$ \\
\hline \multirow{10}{*}{$\begin{array}{l}\text { Procesos } \\
\text { visuales }\end{array}$} & \multirow{5}{*}{ Narrativos } & \multirow[b]{2}{*}{ Acción } & Transaccionales & & \\
\hline & & & $\begin{array}{l}\text { No } \\
\text { transaccionales }\end{array}$ & & \\
\hline & & \multirow[b]{2}{*}{ Reacción } & Transaccionales & & \\
\hline & & & $\begin{array}{l}\text { No } \\
\text { transaccionales }\end{array}$ & & \\
\hline & & Compuestos & & 9 & $64,28 \%$ \\
\hline & \multirow{3}{*}{ Conceptuales } & Analíticos & & & \\
\hline & & Clasificatorios & & & \\
\hline & & Simbólicos & & & \\
\hline & \multirow{2}{*}{ Proyectados } & Mentales & & 5 & $35,71 \%$ \\
\hline & & Verbales & & & \\
\hline
\end{tabular}

Tabla 1. Valores absolutos y porcentuales de los procesos visuales en 10,000 Dresses.

A continuación, se analiza cómo las elecciones concretas en los patrones visuales de transitividad inciden en la representación de los personajes masculinos de estos dos libros álbum con sensibilidades diferentes. 


\section{Personajes masculinos que cuestionan los estereotipos...}

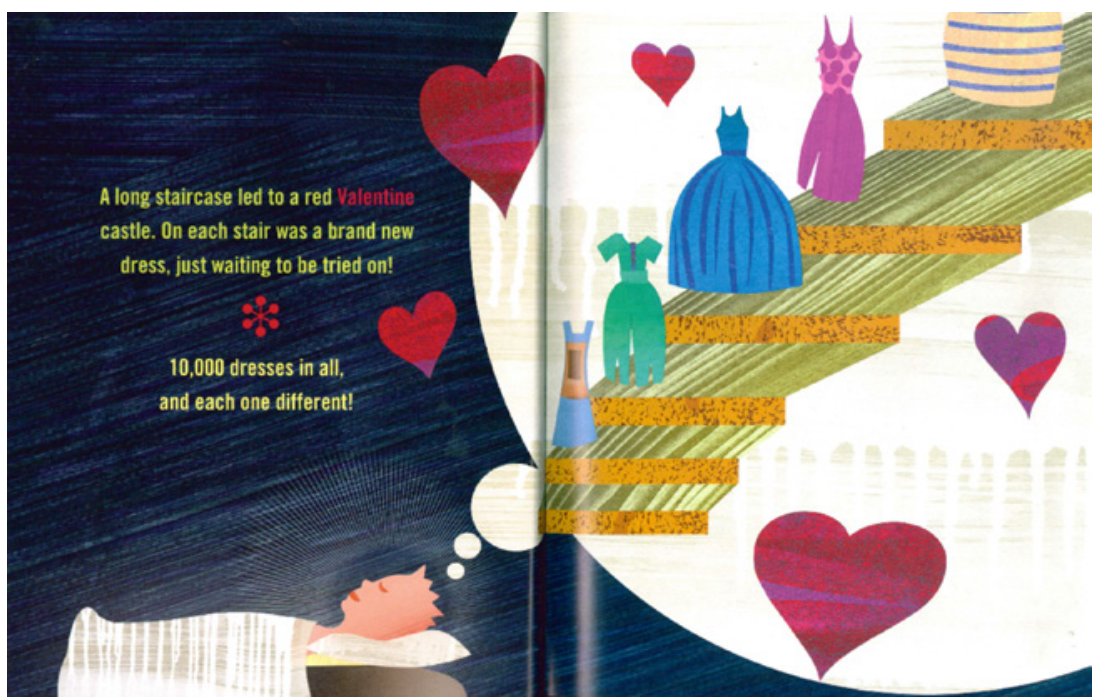

Figura 2. Bailey sueña con vestidos (El texto y la ilustración de esta doble página de 10,000 Dresses escrito por M. Ewert e ilustrado por R. Ray aparecen con el permiso de Copyright (C) Seven Stories Press, 2008).

La representación visual de los/las participantes en 10,000 Dresses corre principalmente a cargo de Bailey, sus familiares y Laurel, pese a que también podemos observar a otros/as participantes, como a unas ovejas que emanan de los sueños de Bailey. Este libro álbum se compone de catorce dobles páginas y de una estructuración simétrica perfecta, como veremos a continuación. Predominantemente, en este libro álbum Rex Ray utiliza imágenes compuestas (embedded) que incluyen procesos de acción y reacción $(64,28 \%$, Tabla 1$)$ y, dentro de estos, encontramos siete transaccionales y dos no transaccionales. El resto de los procesos son mentales de cognición y se expresan mediante globos de pensamiento $(35,71 \%$, Tabla 1). De este modo, por ejemplo, encontramos al protagonista en sueños (doble página segunda, Figura 2) donde, mediante una imagen de proyección mental, se representa visualmente el gran anhelo de Bailey: ponerse vestidos.

En la Figura 2 observamos cómo en esta imagen Bailey proyecta sus sueños mediante globos de pensamiento. Son precisamente estas imágenes de proyección mental de cognición las que desempeñan un papel clave en la representación del personaje principal, ya que son el medio utilizado por el ilustrador, Rex Ray, para expresar las 


\section{Roberto Martínez Mateo}

aspiraciones más profundas de Bailey: llevar fastuosos vestidos. Además, la Figura 2 es también una imagen narrativa de reacción no transaccional cuando nos muestra los fascinantes vestidos con los que sueña Bailey flotando en la escalera. Los corazones de distintos tamaños que rodean a los vestidos ponen de relieve el amor que Bailey siente por sus vestidos. De esta forma, Rex Ray se sirve de una combinación de imágenes de proyección mental y compuestas de acción-reacción para destacar el transgenerismo de Bailey (dobles páginas segunda, tercera, sexta y novena).

Además, este libro álbum presenta una secuencia estructural tripartita (Tabla 2) que se repite en tres ocasiones (una con cada uno de los familiares: madre, padre y hermano del protagonista):

- la primera parte, de proyección mental, es utilizada por el ilustrador para presentar los sueños del protagonista (dobles páginas tercera, sexta y novena);

- la segunda parte, la fase narrativa de acción-reacción no transaccional, se ocupa de plasmar el encuentro de Bailey con cada uno/una de los/las PR, mediante representaciones metonímicas de los personajes (Moya 2019) (dobles páginas cuarta, séptima y décima);

- finalmente, en la tercera parte, se ubica la narrativa de acción-reacción mediante ilustraciones que muestran las reacciones de Bailey frente a los comportamientos de los/las otros/as PR (dobles páginas quinta, octava y undécima).

Veamos con un poco más de detalle cada una de las partes de estas tres secuencias narrativas. En la primera parte, tras la ensoñación inicial que nos presenta a Bailey y sus anhelos (Figura 2), Bailey aparece fantaseando con los tres vestidos que se describen en la primera parte (Tabla 2). Aquí, el ilustrador se sirve de los procesos mentales para representar los sueños de Bailey mediante imágenes de proyección mental materializadas en burbujas de pensamiento donde aparece con diferentes vestidos. Estas ilustraciones representan la voluntad del personaje principal de ponerse vestidos. Además, el hecho de que estas burbujas de pensamiento broten de la cabeza de Bailey y su tamaño aumente progresivamente simboliza que proceden de lo más profundo de su ser.

El uso de las escalas es un elemento visual destacado en la narración de la historia para expresar la cercanía o lejanía, tanto física como sentimental, de Bailey respecto a sus familiares y a Laurel, la vecina. En todas las dobles páginas de esta parte (tercera, sexta y novena), Bailey aparece en primer plano y representado con un gran tamaño, ocupando toda la burbuja de pensamiento. Mediante imágenes narrativas de reacción no transaccional, Bailey mira fijamente al/a la lector/a, buscando su empatía.

En la segunda parte de la secuencia narrativa se van presentando al/a la lector/a los familiares de Bailey. Tras soñar con un vestido, el personaje principal se aproxi- 


\section{Personajes masculinos que cuestionan los estereotipos...}

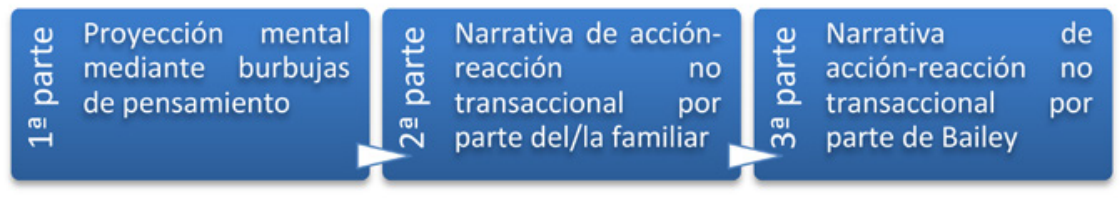

Tabla 2. Estructuración de los procesos verbales de 10,000 Dresses.

ma a sus familiares, madre, padre y hermano (dobles páginas cuarta, séptima y décima). Quiere contarles su sueño y compartir con ellos/ella sus sentimientos. Sus familiares se presentan al/a la lector/a realizando distintas tareas, de acuerdo con un punto de vista tradicional de la distribución de tareas en el hogar: la madre corta los cupones de descuento para velar por la economía familiar (doble página cuarta), el padre realiza tareas de jardinería (doble página séptima) y el hermano juega al fútbol con sus amigos (doble página décima). Sin embargo, es llamativo que su representación sea parcial, ya que nunca se llega a verlos/la de cuerpo entero. De acuerdo con Painter et al. (2013: 60-66), la manifestación de la narrativa visual de los personajes puede ser de dos tipos: completa, cuando la representación del personaje incluye la cara o la cabeza; y metonimica, cuando la representación visual de un personaje se efectúa únicamente mediante una parte de su cuerpo. Así, en esta segunda parte, el ilustrador únicamente nos muestra una parte del/de la PR en una representación metonímica (el brazo de la madre y del padre y las piernas del hermano). Además, en todas las secuencias, Bailey se aproxima a sus familiares lleno de felicidad y optimismo, como muestran su mirada alegre, intentando entablar contacto visual con ellos/ella, y sus brazos alzados, en signo de demanda de atención, mientras sus familiares realizan alguna acción (la madre corta cupones, el padre arranca malas hierbas y el hermano juega al fútbol). La ausencia de correspondencia se muestra a través de imágenes compuestas de acción-reacción no transaccionales. En las tres ocasiones, la ausencia de contacto visual con sus familiares pone de manifiesto la falta de comprensión, reciprocidad y apoyo hacia Bailey. No será hasta la doble página duodécima donde, también a través de una representación metonímica (mano con aguja) mediante una imagen narrativa de reacción transaccional, Bailey encuentra a Laurel, su vecina, y la tan ansiada comprensión.

En esta segunda fase y en relación con las escalas y la posición que ocupa Bailey, observamos que Bailey está ahora representado con un tamaño medio y en un plano medio, reflejando cierto distanciamiento tanto físico como emocional de sus familiares. 


\section{Roberto Martínez Mateo}

En la tercera parte de la secuencia o fase narrativa de acción, Bailey se representa ubicado en un alejado segundo plano, con un tamaño incluso muy inferior al de su engrandecido familiar, y con los brazos caídos y la mirada baja para representar la profunda decepción que sufre al comprobar que sus pretensiones no son bien acogidas por sus familiares. Para ello, el ilustrador utiliza imágenes combinadas de acción-reacción transaccionales, pero no bidireccionales. Así, hallamos a un diminuto Bailey que mira descorazonado al suelo mientras su agigantado/a interlocutor/a (el/la familiar de turno) le observa con desdén (como muestran la representación de la madre con los brazos cruzados, del padre con las manos en los bolsillos y de su hermano con el balón quieto a los pies).

Por su parte, Rex Ray representa a la madre, al padre y al hermano de cuerpo sin cabeza (o al menos completo), con un tamaño muy superior (dobles páginas quinta, octava y undécima) y de espaldas. En ningún momento en todo el álbum vemos la cara a ningún miembro de su familia, que siempre están de espaldas, simbolizando visualmente el rechazo de su entorno a su transgenerización. Además, la ausencia de contacto visual entre Bailey y sus familiares vuelve a recalcar y aumentar aún más la distancia y separación física y emocional. En consecuencia, estas imágenes de reacción transaccionales aunque, sin embargo, no bidireccionales, sirven también para reforzar la idea de que a Bailey, y a los/las niños/as transgénero por extensión, se les aísla y margina, se les da la espalda.

La tendencia ofrecida en estas secuencias narrativas se ve alterada en la doble página decimotercera donde Laurel, pese a aparecer inicialmente también representada metonímicamente (su mano sujetando una aguja, doble página duodécima), es el único personaje que muestra cercanía con el niño transgénero, ya que aparece junto a él. Esto se representa mediante una imagen compuesta de acción-reacción, en la que Laurel se solidariza con los sentimientos del protagonista al aparecer a su lado. Además, es el único personaje, aparte de Bailey, que establece conexión visual con el/la lector/a, para así dejar en manos del/de la lector/a ese espacio interpretativo y que tome su posicionamiento moral.

En la última doble página (decimocuarta), a través de imágenes compuestas de acción-reacción, los rostros de Bailey y Laurel se muestran reflejados en unos espejos como metáfora de que, finalmente, han encontrado a su verdadero yo, y Bailey ha logrado la aceptación y el apoyo que tanto perseguía en Laurel, una joven que le ayuda a hacer sus sueños realidad.

El otro libro álbum analizado, The Purim Superhero, consta de trece dobles páginas y dos páginas sencillas, en total también veintiocho páginas. En ellas, el patrón de transitividad mayoritario que arroja el análisis visual se compone también, como en el caso de 10,000 Dresses, de imágenes compuestas de acción-reacción de carácter transaccional, pero en este caso en combinación con los procesos verbales o de 
comunicación $(92,85 \%$ conjuntamente, Tabla 3$)$. Por otra parte, aunque tan solo representen únicamente un pequeño porcentaje (14,28\%, Tabla 3), los procesos mentales también son relevantes en la representación de Nate en The Purim Superhero ya que es ahí donde Mike Byrne escenifica su gran dilema (doble página séptima). Por último, las imágenes narrativas de acción no transaccional solo representan el $7,14 \%$ de los elementos identificados en las ilustraciones, tal y como se puede observar en la Tabla 3 .

\begin{tabular}{|c|c|c|c|c|c|}
\hline \multicolumn{4}{|c|}{ PATRONES DE TRANSITIVIDAD EN 10,000 DRESSES } & $\begin{array}{l}\text { Valores } \\
\text { absolutos }\end{array}$ & $\begin{array}{l}\text { Valores } \\
\text { relativos }\end{array}$ \\
\hline \multirow{10}{*}{$\begin{array}{l}\text { Procesos } \\
\text { visuales }\end{array}$} & \multirow{5}{*}{ Narrativos } & \multirow[b]{2}{*}{ Acción } & Transaccionales & & \\
\hline & & & $\begin{array}{l}\text { No } \\
\text { transaccionales }\end{array}$ & 2 & $7,14 \%$ \\
\hline & & \multirow[b]{2}{*}{ Reacción } & Transaccionales & & \\
\hline & & & $\begin{array}{l}\text { No } \\
\text { transaccionales }\end{array}$ & & \\
\hline & & Compuestos & & 22 & $78,57 \%$ \\
\hline & \multirow{3}{*}{ Conceptuales } & Analíticos & & & \\
\hline & & Clasificatorios & & & \\
\hline & & Simbólicos & & & \\
\hline & \multirow{2}{*}{ Proyectados } & Mentales & & 4 & $14,28 \%$ \\
\hline & & Verbales & & & \\
\hline
\end{tabular}

Tabla 3. Valores absolutos y porcentuales de los procesos visuales en The Purim Superhero.

Efectivamente, en numerosas ocasiones observamos cómo los/las PR se muestran en imágenes compuestas combinadas con representaciones visuales de proyección verbal, hecho que se evidencia visualmente por aparecer con la boca abierta. Esto pone de manifiesto la comunicación fluida que se establece entre Nate y sus padres o Nate y el resto de sus compañeros/as de clase (por ejemplo, en las dobles páginas primera, tercera, cuarta y quinta). A esto se suman los vectores visuales que conectan las miradas de Nate y sus respectivos/as interlocutores/as (padres o compañeros/as) mediante imágenes de reacción transaccionales, lo que pone de relieve visualmente la comprensión y aceptación que halla el joven protagonista en su entorno $(78,57 \%$, Tabla 3). Uno de estos ejemplos aparece en la Figura 3 (doble página sexta) en la que Nate establece contacto visual con uno de sus padres, Abba, mientras este último aparece representado con la boca abierta, en una imagen de proyección verbal tran- 


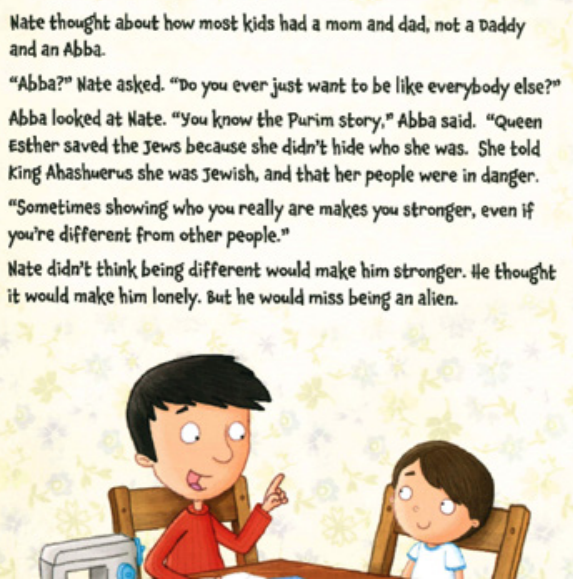

Figura 3. Nate charlando con uno de sus padres mientras hacen patrones (El texto y la ilustración de esta doble página de The Purim Superhero escrito por Elizabeth Kushner, ilustrado por Mike Byrne (C2013 aparecen con el permiso de Kar-Ben Publishing, www.karben.com).

sitiva, para manifestar gráficamente en la ilustración que están manteniendo una conversación. Abba pregunta a Nate si ya ha elegido cuál será su disfraz y, al percibir dudas en Nate, Abba apunta que no necesariamente todos/as los/las niños/as tienen que ser iguales. Simultáneamente, se puede apreciar el contacto visual entre las miradas de ambos participantes en una imagen narrativa de reacción transaccional. Por lo tanto, esta conversación se representa mediante una imagen narrativa compuesta de carácter transaccional combinada con otra de proyección verbal.

Una escena similar a esta se repite en las dobles páginas séptima y octava donde Nate sigue conversando con Abba mientras este le narra la historia de Purim, la reina judía que salvó a su pueblo, y donde Daddy le reafirma ante sus dudas acerca de qué disfraz elegir en el momento de acostarse. En la doble página sexta, al tiempo que Daddy le define las cualidades que hacen de alguien un superhéroe, también se aprecia cómo le acaricia cariñosamente la cabeza para confortarle en una imagen narrativa compuesta de carácter transaccional. En todo momento, ambos padres muestran su apoyo a Nate, lo que se manifiesta visualmente mediante los vectores visuales que establecen en una imagen de proyección verbal. No obstante, y pese al apoyo incondicional de sus dos padres a Nate, dejan que sea él quien tome la decisión final. 


\section{Personajes masculinos que cuestionan los estereotipos...}

Nuevamente, en las páginas correspondientes al desfile final (dobles páginas undécima, duodécima, decimotercera y decimocuarta) encontramos ilustraciones que combinan imágenes narrativas de acción y reacción con otras de proyección verbal representadas mediante las bocas abiertas de los/las PR, siendo este el patrón de ocurrencia más común en el libro álbum.

Únicamente en dos ocasiones encontramos cómo Nate mira directamente al/a la lector/a buscando su complicidad en la trama (dobles páginas duodécima y decimotercera). En la doble página decimotercera vemos cómo Nate se une al desfile junto con sus compañeros/as (vestido de alienígena) ocupando el último lugar de la fila. En esta ocasión, establece vectores visuales con el/la lector/a mediante una imagen narrativa de reacción transaccional mientas le hace el gesto, con el dedo índice delante de los labios, de que guarde silencio para no revelar su secreto. Así pretende hacer partícipe al/a la lector/a de su decisión final, de ser fiel a sí mismo, pese a ser diferente. En la siguiente doble página (decimotercera), Nate aparece detrás de sus compañeros/as en un alejado segundo plano. Desde allí, vuelve a conectar visualmente con el/la lector/a, ahora con mirada triste y ojos vidriosos porque parece ser el único sin premio en el concurso de disfraces. Sin embargo, en la doble página decimocuarta aparecen sus padres (Abba y Daddy) y su hermana (Miri) sonrientes observando alegres cómo Nate recibe el premio al disfraz más original. Finalmente, Nate recibe el reconocimiento social que reafirma su decisión y su valentía de optar por lo diferente.

\subsection{Sinergia texto-imagen}

A continuación, se analiza la contribución relativa y las relaciones sinérgicas entre el modo verbal y visual mediante el estudio de cómo se actualizan las opciones de significación en ambos modos semióticos. Comenzamos por analizar el compromiso sistémico en dos dominios narrativos clave: la acción y el personaje (Painter et al. 2013: 143). En términos generales, el potencial significativo que se actualiza en el sistema de transitividad verbal y visual es similar en los dos modos semióticos tanto en 10,000 Dresses como en The Purim Superhero.

Respecto a la caracterización del personaje y las acciones que lleva a cabo, la estructura tripartita repetitiva permite a Bailey mostrar su "amor" por los diferentes vestidos ("Bailey loved the dress made of [...]", doble página tercera, sexta y novena) mediante procesos verbales volitivos $(34,37 \%$, Gráfico 1$)$. De la misma forma, los procesos materiales $(53,12 \%$, Gráfico 1$)$ son muestra de la determinación y tenacidad por lograr hacer realidad sus sueños. Pese a ser rechazado, Bailey lo intenta con todos sus familiares. Concretamente, en 10,000 Dresses, en el modo verbal, Marcus Ewert emplea procesos materiales y mentales (87,49\%, Gráfico 1) para narrar la lucha interna en la que se debate Bailey y las acciones que lleva a cabo 


\section{Roberto Martínez Mateo}

para conseguir su sueño. A su vez, estos procesos narrativos en el modo verbal se complementan en el modo visual con una mayoría de imágenes compuestas que combinan procesos visuales de acción y reacción.

Ejemplos de complementariedad en el compromiso sistémico entre modos se observan en la primera parte (Tabla 2) de la estructura del libro cuando Rex Ray muestra a Bailey soñando con sus vestidos, en imágenes de proyección mental en burbujas de pensamiento, y Marcus Ewert los describe verbalmente en detalle. A través de la complementación de ambos modos semióticos es como autor e ilustrador de 10,000 Dresses transmiten un mensaje progresivo de respeto por la diversidad y por los/las niños/as transgénero.

En The Purim Superhero, también se da la complementariedad entre las ilustraciones de Mike Byrne y el texto de Elisabeth Kushner en todas las ocasiones en que Abba y Daddy apoyan a Nate en su diatriba. Por ejemplo, en la página 15, donde, verbalmente, Nate pregunta a Abba si le coserá el disfraz que elija, a lo que Abba contesta que por supuesto. Visualmente, la ilustración muestra cómo se establece una conexión de los vectores visuales para simbolizar la empatía y conexión entre ambos. No obstante, esta conexión entre Abba y Nate es más evidente en el modo visual que en el verbal. Además, en la mayor parte de las ilustraciones encontramos a los/las PR con la boca abierta en clara representación de la comunicación que existe entre Nate y sus padres y compañeros/as.

Sin embargo, también se han identificado imágenes en las que no existe la complementariedad en el compromiso sistémico con el modo escrito. Aquellas en las que las imágenes compuestas se combinan con otras de proyección verbal que añaden una carga significativa que solo aporta el modo visual. Este es el caso de las dobles páginas cuarta, séptima y décima, correspondientes a la segunda parte (Tabla 2), que muestran a un Bailey ilusionado que se aproxima a cada uno de sus familiares para contarles sus sueños y estos le rechazan. En las tres ocasiones que se dirige a ellos/ella, la actitud de Bailey únicamente se describe en las ilustraciones: sonriente con los brazos alzados en signo de entusiasmo en una imagen narrativa de acción-reacción no transaccional, mientras que el modo verbal únicamente refleja la acción mediante un proceso narrativo material ("Bailey woke up, and went to find Mother/Father/ her brother”, respectivamente).

Un ejemplo de divergencia de emparejamiento en The Purim Superhero se halla en la antepenúltima doble página duodécima. Nate marcha en última posición del desfile mientras mira fijamente al/a la lector/a y le indica con un gesto que no revele su disfraz. Este proceso visual narrativo de reacción transaccional con el/la lector/a no tiene equivalente en el modo verbal, ya que la ilustración carece de texto. Por tanto, esta ausencia de convergencia entre el modo visual y el verbal genera en los/las lectores/as la necesidad de extraer su propio posicionamiento 


\section{Personajes masculinos que cuestionan los estereotipos...}

moral sobre lo que leen y ven. Finalmente, siguiendo el consejo de sus padres, Nate decide ser fiel a sí mismo y disfrazarse de alienígena, cumpliendo con sus deseos, pese a ser diferente.

\section{Discusión final y conclusión}

El análisis de la sinergia texto-imagen nos ha mostrado la relevancia de esta relación en la construcción del significado en 10,000 Dresses y en The Purim Superhero y la complejidad de descifrar la carga significativa que comporta el modo visual. Mientras que, en términos generales, los procesos narrativos verbales se pueden sintetizar en un tipo de proceso, en la narrativa visual abundan los procesos combinados de acción-reacción con imágenes de proyección verbal. Consecuentemente, en los libros álbum analizados la imagen contribuye en mayor medida al desarrollo de la trama narrativa al ofrecer más cantidad de información que la palabra. Esta afirmación se puede hacer extensible a otros muchos ejemplos. Además, es reseñable mencionar que Nodelman (1988) corroboró que el hecho de analizar los recursos que utilizan los distintos medios (escrito y visual) para construir significaciones aumenta el interés de los/las niños/as en los libros álbum que tienen entre manos. Dado que tanto los libros álbum analizados, como otros muchos que proliferan en la actualidad, están principalmente dirigidos a niños/as de edades tempranas que todavía están en proceso de desarrollo cognitivo, es fundamental que los/las jóvenes alumnos/as reciban una instrucción explícita (Doonan 1993) sobre los sistemas que operan en la construcción de significados en el modo semiótico visual (Unsworth y Wheeler 2002: 69).

En un mundo donde la cultura es cada vez más multimodal, ya que se produce y se transmite a través de múltiples soportes, tecnologías y empleando diversos lenguajes de representación, es necesario que los/las jóvenes dispongan de una alfabetización visual que les permita descifrar los complejos y sofisticados mensajes que se divulgan. Los libros álbum son un recurso con alta carga multimodal y un valiosísimo instrumento para que el/la joven lector/a desarrolle múltiples capacidades. Así, para descifrar los sofisticados mensajes que encierran las imágenes es necesaria una adecuada formación sobre las estrategias que emplean los/las creadores/as del lenguaje visual. Por ello, es preciso y urgente introducir en la Educación Primaria elementos curriculares que formen a los/las niños/as en las destrezas y capacidades necesarias para decodificar la compleja carga narrativa que comporta el modo visual, y poder así comprender el papel que desempeña en su interacción con la palabra en la construcción del significado global. 


\section{Agradecimientos}

El presente estudio se ha realizado al amparo del proyecto de investigación FFI2017-85306-P (LA CONSTRUCCIÓN DEL DISCURSO EN LOS LIBROS-ÁLBUM INFANTILES QUE CUESTIONAN ESTEREOTIPOS DE GÉNERO Y EL CONCEPTO DE FAMILIA TRADICIONAL. UN ANÁLISIS MULTIMODAL - AMULIT), financiado por el Ministerio de Economía, Industria y Competitividad (2018-2020).

\section{Libros álbum}

Ewert, Marcus y Rex Ray. 2008. 10,000 Dresses. Nueva York: Seven Stories Press. Kushner, Elisabeth y Mike Byrne. 2013. The Purim Superhero. Mineápolis, Minesota: Kar-Ben Publishers.

1. La tipografía de este libro álbum bien merece un estudio aparte más extenso dada la riqueza que alberga. Rex Ray, el ilustrador, emplea una paleta de colores en las letras en función de la persona que habla o el elemento al que se refiere. Por ejemplo, cuando describe los vestidos que imagina Bailey, dota los elementos característicos de cada uno de ellos de colores representativos.
Así, al describir el vestido hecho de cristales que tintinean al chocar los unos con los otros, el sustantivo "crystals" aparece en color azul. De igual forma, continúa describiendo el efecto que produce la luz al reflejarse en los cristales, que se asemeja al de un arcoíris (rainbow) y utiliza una tonalidad para cada una de las letras del término "rainbows", como si del propio arcoíris se tratase.

\section{Obras citadas}

Caldas-Coulthard, Carmen y Malcolm Coulthard. (eds.) 1996. Text and Practices: Readings in Critical Discourse Analysis. Londres: Routledge.

CAssany, Daniel. 2006. Tras las líneas. Sobre la lectura contemporánea. Barcelona: Anagrama.

CerRillo, P. César. 2010. Sobre lectura, literatura y educación. México: Miguel Ángel Porrua.
COHEN, Louis, Lawrence MANion y Keith MoRRIson. 2007. Research Methods in Education. Londres: Routledge.

Colomer, Teresa. 2018. “Research and training of professionals in the field of children's and young adult literature". Bellaterra Journal of Teaching \& Learning Language \& Literature 11: 9-26. 


\section{Personajes masculinos que cuestionan los estereotipos...}

Cope, Bill y Mary Kalantzis. 2009." Multiliteracies: New Literacies, New Learning". Pedagogies: An International Journal 4 (3): 164-195.

DoonAn, Jane. 1993. Looking at Pictures in Picture Books. Stroud:Thimble Press.

Duff, Alan y Adan Maley. 1990. Literature. Oxford: Oxford U.P.

Evans, Janet. (ed.) 2015. Challenging and Controversial Picturebooks: Creative and Critical Responses to Visual Texts. Londres y Nueva York: Routledge.

Evans, Judith. 1995. Feminist Theory Today: An Introduction to Second-Wave Feminism. Londres: Sage.

FalRclough, Norman. 2003. Analysing Discourse:Text Analysis for Social Research. Londres: Routledge.

FERnÁNDEZ, Marisa. 1996. Traducción y literatura juvenil: narrativa anglosajona contemporánea en España. León: Universidad de León.

Gooden, Angela M. y Mark A. Gooden, 2001. "Gender representation in notable children's picture books: 1995-1999". Sex Roles 45 (1/2): 89-101. DOI: 10.1023/A:1013064418674

HallidAY, M.A.K. 2004. Introduction to Functional Grammar. $3^{\text {rd }}$ edition. Londres: Arnold.

HANÁN DíAz, Fanuel. 2007. Leer y mirar el libro álbum: ¿un género en construcción? Bogotá: Norma.

Healy, Annah. 2007. Multiliteracies and Diversity in Education: New Pedagogies for Expanding Landscapes. South Melbourne, Vic.: Oxford U.P.

Kalantzis, Mary y Bill Cope. (eds.) 2001. Transformations in Language and Learning. Perspectives on Multiliteracies. Melbourne: Common Ground Publishing.

Kress, Gunther. 2010. Multimodality: A Social Semiotic Approach to Contemporary Communication. Londres: Routledge.

Kress, Gunther y Theo van Leeuwen. (1996) 2006. Reading Images: The Grammar of Visual Design. Londres: Routledge Press.

Kümmerling-Meibauer, Bettina. 2015. "From baby books to picturebooks for adults: Euro- pean picturebooks in the new millennium". Word \& Image 31 (3): 249-264. DOI: $10.1080 / 02666286.2015 .1032519$

Kümmerling-Meibauer, Bettina, Jörg Meibauer, Kerstin NACHTIGÄLlER y Katharina J. ROHLFING. (eds.) 2015. Learning from Picturebooks: Perspectives from Child Development and Literacy Studies. Londres: Routledge.

LEMKE, Jay. 1998. "Multiplying Meaning:Visual and Verbal Semiotics in Scientific Texts". In Martin, Jim y Robert Veel (eds.) Reading Science: Critical and Functional Perspectives on Discourses of Science. Londres: Routledge: 87-113.

LewIS, David. 2001. Reading Contemporary Picturebooks: Picturing Text. Londres: RoutledgeFalmer.

Martínez Lirola, María. 2019. “Approaching the construction of multimodal masculinity in a sample of picture books with two-men families". Asparkía 34: 87-105.

Martínez Lirola, María. En prensa. “Compositional and interpersonal analysis of the picture book Stella brings the family: deconstructing affection". Onomázein 55. DOI: 10.7764/onomazein.55.01

MILlÁN, José Antonio. 2000. “La lectura y la sociedad del conocimiento" [publicación en línea]. Madrid: Federación de Gremios de Editores de España. <http://jamillan.com/lecsoco. htm $>$ [Fecha de consulta: 15 de septiembre de 2020].

Mills, Sara. 2008. Language and Sexism. Cambridge: Cambridge U.P.

Moya Guijarro, A. Jesús. 2014. A Multimodal Analysis of Picture Books for Children. A Systemic Functional Approach. Londres: Equinox.

Moya Guijarro, A. Jesús. 2019. "Textual functions of metonymies in Anthony Browne's picture books: A multimodal approach". Text and Talk 39 (3): 389-413. DOI: 10.1080/ 00437956.2019 .1670932

Moya Guijarro, A. Jesús y Cristina Cañamares TorRIJOS. En prensa. “Un análisis multimodal de los elementos circunstanciales y ambientes de libros álbum que rompen estereotipos de género". Estudios Filológicos 66. 


\section{Roberto Martínez Mateo}

Nodelman, Perry. 1998. Words about Pictures. The Narrative Art of Children's Picture Books. Atenas, Georgia: University of Georgia Press.

PAINTER, Clare. 2007. “Children's picture books narratives: Reading sequences of images". En McCabe, Anne, Mike O'Donnell y Rachel Whittaker (eds.) Advances in Language and Education. Londres/Nueva York: Continuum: 40-59.

PAINTER, Clare. 2008. "The Role of Colour in Children's Picture Books: Choices in Ambience". En Unsworth, Len (ed.) New Literacies and the English Curriculum: Multimodal Perspectives. Londres: Continuum: 89-111.

Painter, Clare, Jim Martin y Len Unsworth. 2013. Reading Visual Narratives: Image Analysis of Children's Picture Books. Sheffield: Equinox.

SERAFINI, Frank. 2010. "Reading multimodal texts: perceptual, structural and ideological perspectives". Children's Literature in Education 41: 85-104.

Serafini, Frank. 2012. “Expanding the Four Resources Model: Reading visual and multimodal texts". Pedagogies: An International Journal 7 (2): 150-164.

Shavit, Zohar. 1986. Poetics of Children's Literature. Atenas, Georgia: University of Georgia Press.
SundeRlAND, Jane. 2012. Language, Gender and Children's Fiction. Londres: Continuum.

TAYLOR, Frank. 2003. "Content Analysis and Gender Stereotypes in Children's Books". Teaching Sociology 31: 300-311.

UNSWORTH, Len. 2001. Teaching multiliteracies across the curriculum: Changing contexts of text and image in classroom practice. Filadelfia: Open U.P.

UNSWORTH, Len. 2006. "Towards a Metalanguage for Multiliteracies Education: Describing the Meaning-Making Resources of Language-Image Interaction". English Teaching: Practice and Critique 5 (1): 55-76.

UNSWORTH, Len. 2014. "Multimodal reading comprehension: Curriculum expectations and large-scale literacy testing practices". Pedagogies: An International Journal 9: 26-44.

Unsworth, Len e Isabel Ortigas. 2008. “Exploring the Narrative Art of David Wiesner: Using a Grammar of Visual Design and Learning Experiences on the World Wide Web". Educational Studies of Language and Literature 8 (3): 1-21.

UnSWORTH, Len y Janet WheELeR. 2002. “Revaluing the role of images in reviewing picture books". Reading 36 (2): 68-74. 